\title{
FERMENTAÇÃO E COMPOSIÇÃO BROMATOLÓGICA DA SILAGEM DE CANA-DE-AÇÚCAR INOCULADA COM LACTOBACILLUS BUCHNERI, ASSOCIADA OU NÃO À ADIÇÃO DE FONTES DE CARBOIDRATOS
}

\author{
FERMENTATION AND BROMATOLOGICAL COMPOSITION OF SILAGE OF \\ SUGARCANE INOCULATED WITH LACTOBACILLUS BUCHNERI, WITH OR \\ WITHOUT THE ADDITION OF CARBOHYDRATE SOURCES
}

\author{
Nakali Evelize Caregnato'1 ORCID - http://orcid.org/0000-0001-7637-9254 \\ Luis Fernando Glasenapp de Menezes ${ }^{1}$ ORCID - http://orcid.org/0000-0002-3543-8294 \\ Fabiana Luiza Matielo de Paula1 ORCID - http://orcid.org/0000-0002-0443-5437 \\ João de Assis Farias Filho ${ }^{*}$ ORCID - http://orcid.org/0000-0002-4821-074X \\ Felipe Carneiro ${ }^{1}$ ORCID - http://orcid.org/0000-0002-2706-3648 \\ José Henrique Ignácio Baraviera1 ORCID - http://orcid.org/0000-0001-5056-9607 \\ 'Universidade Tecnológica Federal do Paraná, Dois Vizinhos. PR, Brasil. \\ *Autor para correspondência - joaodeassis13@hotmail.com
}

\begin{abstract}
Resumo
Avaliaram-se os aspectos fermentativos e bromatológicos da silagem de cana-de-açúcar com adição de inoculante à base de Lactobacillus buchneri, associado ou não à adição de farelo de trigo (20\%), de casca de soja $(20 \%)$ ou à mistura de farelo de trigo $(10 \%)+$ casca de soja $(20 \%)$, utilizando delineamento inteiramente casualizado, com quatro repetições. Não foram observados efeitos significativos dos tratamentos sobre o $\mathrm{pH}$ da silagem, porém, observou-se temperatura mais elevada no tratamento contendo $10 \%$ de farelo de trigo $+10 \%$ de farelo de soja em relação aos tratamentos controle, CA e CCS20. A adição de fontes de carboidratos proporcionou aumento médio de 145,86 $\mathrm{kg}$ de $\mathrm{MV} / \mathrm{m}^{3}$ nos valores de massa específica e, juntamente com a adição de inoculante biológico, recuperação de matéria seca em média $20,5 \%$ superior ao da silagem controle, além de elevar os teores de matéria seca em média $2,63 \%$ e de proteína bruta em 1,92\%. Conclui-se que, isoladamente, a adição do inoculante biológico foi capaz apenas de reduzir as perdas do processo fermentativo em relação à silagem controle e que a adição de fontes de carboidratos, tanto casca de soja como farelo de trigo, melhora o valor nutritivo da silagem de cana-de-açúcar.
\end{abstract}

Palavras-chave: ensilagem, inoculação, parâmetros fermentativos, valor nutritivo

\begin{abstract}
It was evaluated the fermentative and bromatological aspects of sugarcane silage with addition of Lactobacillus buchneri inoculant with or without the addition of wheat bran (20\%), soybean hull $(20 \%)$ or the mixture of wheat bran $(10 \%)+$ soybean hull $(20 \%)$, using a completely randomized design with four replicates. No significant effects of the treatments on the $\mathrm{pH}$ of the silage were observed, however, a higher temperature was observed in the treatment containing $10 \%$ of wheat bran $+10 \%$ of soybean meal in relation to the control treatment. The addition of carbohydrate sources provided an average increase of $145,86 \mathrm{~kg}$ of $\mathrm{MV} / \mathrm{m}^{3}$ in the specific mass values and, together with the addition of biological inoculant, dry matter recovery averaged $20,5 \%$ higher than the control silage, in addition to increasing the dry matter contents in an average of $2,63 \%$ and crude protein in $1,92 \%$. It is
\end{abstract}


concluded that, in isolation, the addition of the biological inoculant was only able to reduce losses of the fermentative process in relation to the control silage and that the addition of carbohydrate sources, both soybean peel and wheat bran, improve the nutritive value of the cane silage.

Keywords: silage, inoculation, fermentation characteristics, nutritional value

Recebido em: 23 de novembro de 2017.

Aceito em: 13 de julho de 2018.

\section{Introdução}

A cana-de-açúcar é uma gramínea tropical que se destaca pelo seu alto potencial de acúmulo de biomassa e pela facilidade no manejo, tornando-a uma alternativa interessante a ser utilizada na alimentação de ruminantes. Entretanto, seu uso é geralmente feito sobre regime de cortes, sendo conservada no canavial e oferecida aos animais diariamente, o que dificulta sua utilização em larga escala devido às limitações operacionais ${ }^{(1)}$.

A ensilagem da cana-de-açúcar pode ser uma boa alternativa para reduzir as dificuldades operacionais encontradas pelos produtores, porém, de acordo com Valvasori et al. ${ }^{(2)}$, a alta concentração de carboidratos solúveis nesse material caracteriza um relevante problema no seu processo de conservação, devido à produção de etanol e gás carbônico por leveduras que se beneficiam desses açúcares.

Nesse contexto, alguns aditivos vêm sendo utilizados para minimizar as perdas durante a ensilagem. O uso de inoculante biológico contendo Lactobacillus buchneri é uma opção para garantir a estabilidade do processo fermentativo e de conservação da silagem ${ }^{(3)}$, uma vez que essas bactérias são capazes de inibir o metabolismo de leveduras e fungos filamentosos por meio da produção de ácido acético e, consequentemente, reduzir a ocorrência de fermentação alcóolica e de perdas durante a ensilagem ${ }^{(4)}$.

Além disso, o alto teor de umidade geralmente observado em gramíneas tropicais no momento de ensilagem pode ser um inconveniente que dificulte o processo de conservação. Segundo Zanine et al. ${ }^{(5)}$, bactérias do gênero Clostridium são favorecidas em condições de alta umidade, resultando em aumento das perdas por gases em razão do aumento na produção de $\mathrm{CO}_{2}$ e ácido butírico. Nesse sentido, a adição de fontes de carboidratos, como fubá de milho, farelo de trigo, polpa cítrica, casca de soja e outros resíduos de agroindústrias, tem se mostrado eficiente, ao elevar o teor de matéria seca das silagens e aumentar as chances da ocorrência de uma boa fermentação ${ }^{(6)}$, reduzindo a produção de efluentes e aumentando o valor nutritivo das silagens ${ }^{(7)}$.

Em experimentos conduzidos por Ribeiro et al. ${ }^{(8)}$, os autores observaram que a adição de crescentes níveis de farelo de trigo $(0 \%, 8 \%, 16 \%, 24 \%$ e $34 \%)$ na silagem de capim Tanzânia resultou em acréscimo linear nos teores de matéria seca, digestibilidade e proteína bruta, com redução significativa dos teores de fibra em detergente neutro, fibra em detergente ácido, lignina e celulose, chegando os autores à conclusão de que $11 \%$ de inclusão de farelo de trigo seria o nível mínimo para a produção de silagem de capim Tanzânia com qualidade satisfatória. Da mesma forma, Zanine et al..$^{(5)}$ observaram que a adição de $20 \%, 40 \%$ e $60 \%$ de farelo de trigo na silagem de capim Mombaça, além de melhorar seu valor nutritivo, resultou em reduções lineares dos valores de perdas por gases e efluentes e aumentou linearmente a recuperação de matéria seca, chegando os autores à conclusão de que $20 \%$ de inclusão de farelo de trigo seria suficiente para melhorar significativamente a qualidade da silagem 
de capim Mombaça de forma economicamente viável.

Avaliando o uso de produtos alternativos na silagem de capim-elefante, Monteiro et al. ${ }^{(9)}$ observaram que a inclusão de $10 \%$ de casca de soja, além de proporcionar um adequado padrão de fermentação, promoveu aumento de $2,67 \%$ de proteína bruta e redução de $26,9 \%$ de fibra em detergente neutro indigestível em relação à silagem sem aditivos. Nesse aspecto, por apresentar elevada digestibilidade ruminal da fibra, a casca de soja pode ocasionar uma elevada produção de ácidos graxos voláteis no rúmen $^{(10,11)}$, o que melhora o aproveitamento da dieta e pode proporcionar melhor desempenho animal.

Nesse contexto, objetivou-se avaliar a qualidade da silagem de cana-de-açúcar sob efeito do uso de inoculante biológico associado ou não a diferentes porcentagens de farelo de trigo e/ou casca de soja.

\section{Material e métodos}

O experimento foi conduzido na Universidade Tecnológica Federal do Paraná-Campus Dois Vizinhos, localizada na região Sudoeste do estado do Paraná, com latitude de $25^{\circ} 44^{\prime} 57^{\prime}$ ' S, longitude de $53^{\circ}$ 03' 41" W e $534 \mathrm{~m}$ de altitude ${ }^{(12)}$, com clima subtropical úmido do tipo Cfa, segundo a classificação de Köppen.

Foram avaliados os aspectos fermentativos e a composição bromatológica da silagem de cana-deaçúcar submetida a cinco tratamentos na ensilagem: $\mathrm{C}=$ controle; $\mathrm{CA}=$ cana + inoculante biológico (L. buchneri); CCS20 = cana + inoculante $+20 \%$ de casca de soja; CFT20 $=$ cana + inoculante + $20 \%$ de farelo de trigo; CFC20 = cana + inoculante $+10 \%$ de farelo de trigo $+10 \%$ de casca de soja, utilizando o delineamento inteiramente casualizado, com quatro repetições.

A variedade de cana-de-açúcar utilizada foi RB925345, com idade de 10 meses e média de 21,25\% de MS, colhida de um canavial pertencente à Estação Experimental da UTFPR - Dois Vizinhos. A colheita foi realizada de forma manual, e o material foi triturado em picadeira estacionária para obtenção de partículas de tamanho médio de 1,6 cm. Foram retiradas quatro amostras para o tratamento sem aditivos (controle), e o restante foi submetido à mistura com as fontes de carboidratos de acordo com os diferentes tratamentos. Posteriormente, foi borrifado no material o inoculante biológico à base de Lactobacillus buchneri, diluído em água conforme a recomendação do fabricante em quantidade suficiente para obtenção de $3,64 \times 10^{5}$ unidades formadoras de colônia - UFC/g de matéria natural.

Todo material foi ensilado em minissilos confeccionados com tubos de PVC de $100 \mathrm{~mm}$ de diâmetro e $50 \mathrm{~cm}$ de altura. Para a quantificação das perdas por efluentes, foi colocado $1 \mathrm{~kg}$ de areia na parte inferior dos minissilos, utilizando uma tela e um tecido de náilon para separar a areia do material ensilado.

Os minissilos foram vedados com tampão e fita adesiva e pesados em balança analítica antes e depois de preenchidos com a massa de forragem. A partir dos valores de massa obtidos, foi possível quantificar a massa específica da silagem a partir da razão entre a massa ensilada (kg de MV) pelo volume de silo ocupado $\left(\mathrm{m}^{3}\right)$.

Após 60 dias de armazenamento, os minissilos foram novamente pesados em balança analítica com e sem a massa ensilada, sendo possível quantificar as perdas por gases (PG) e perdas por efluentes (PE), segundo metodologias indicadas por Jobim et al. ${ }^{(13)}$ : 


$$
\mathrm{PG}=\frac{((\text { PCen }- \text { Pen }) * \text { MSen })-((\text { PCab }- \text { Pen }) * M S a b)}{((\text { PCen }- \text { Pen }) * \text { MSen })}
$$

onde:

$\mathrm{PG}=$ Perdas por gases em $\%$ da MS

PCen $=$ Peso do silo cheio na ensilagem $(\mathrm{kg})$

Pen $=$ Peso do conjunto $($ silo + tampa + areia + tela + pano $)$ na ensilagem $(\mathrm{kg})$

MSen $=$ Teor de MS da forragem na ensilagem (\%)

$\mathrm{PCab}=$ Peso do silo cheio na abertura $(\mathrm{kg})$

$\mathrm{MSab}=$ Teor de MS da forragem na abertura (\%)

$$
\mathrm{PE}=\frac{P a b-P e n}{M V f e} \times 1000
$$

onde:

$\mathrm{PE}=$ Produção de efluentes (kg ton-1 de MV)

$\mathrm{Pab}=$ Peso do conjunto $($ silo + areia + pano + tela $)$ na abertura $(\mathrm{kg})$

Pen $=$ Peso do conjunto $($ silo + areia + pano + tela $)$ na ensilagem $(\mathrm{kg})$

MVfe $=$ Massa verde de forragem ensilada $(\mathrm{kg})$

$$
\mathrm{RMS}=\frac{M F a b \times M S a b}{M V f e \times M S f e} \times 100
$$

onde:

RMS = índice de recuperação de matéria seca

$\mathrm{MFab}=$ massa de forragem na abertura

$\mathrm{MSab}=$ teor de MS na abertura

MFfe $=$ massa de forragem no fechamento

$\mathrm{Msfe}=$ teor de MS da forragem no fechamento 
No momento da abertura dos silos, realizaram-se as medidas da temperatura, utilizando termômetros posicionados no centro geométrico da massa de forragem de cada minissilo. Em seguida, a silagem foi retirada dos minissilos, pesada e colocada separadamente sobre uma lona plástica para homogeneização, de onde foi coletada uma amostra por unidade experimental para determinação do $\mathrm{pH}$ utilizando potenciômetro digital, conforme metodologia proposta por Silva e Queiroz ${ }^{(14)}$.

Foi retirada uma amostra de cada unidade experimental, pesada, acondicionada em saco de papel e mantida em estufa de ventilação forçada a $60^{\circ} \mathrm{C}$ por 72 horas. Posteriormente, essas amostras foram retiradas da estufa e expostas à temperatura ambiente até peso constante, pesadas para determinação da matéria pré-seca, sendo logo após processadas em moinho tipo "Willey" com peneira de malha de $1 \mathrm{~mm}$ e armazenadas em vidros tampados para posteriores análises dos valores de matéria seca (MS), proteína bruta (PB), fibra a detergente neutro (FDN), fibra a detergente ácido (FDA), matéria mineral $(\mathrm{MM})$ e matéria orgânica (MO), segundo recomendações de Silva e Queiroz ${ }^{(14)}$.

Os dados foram submetidos à análise de variância e, quando significativas, as médias foram comparadas pelo teste de Tukey a $5 \%$ de probabilidade.

\section{Resultados e discussão}

Os valores de $\mathrm{pH}$ da silagem não apresentaram diferenças significativas entre os tratamentos (Tabela 1). Ao avaliarem diferentes teores de carboidratos solúveis (CHOs) e seus efeitos sobre as características da silagem de cana-de-açúcar, Da Silva et al. ${ }^{(15)}$ observaram aumento linear do $\mathrm{pH}$ à medida que diminuíram os teores de CHOs, com valores variando entre 3,36 a 3,44. Entretanto, neste ensaio, a adição de diferentes tipos e níveis de fontes de carboidratos não foi suficiente para causar efeitos significativos sobre o $\mathrm{pH}$ da silagem, porém, a adição de inoculante biológico pode ter influenciado na manutenção do $\mathrm{pH}$, visto que a utilização de Lactobacillus buchneri pode inibir o metabolismo de leveduras e fungos devido à produção de ácido acético, evitando que esses microrganismos possam consumir ácido lático e assim ocasionando elevação no $\mathrm{pH}$ da silagem ${ }^{(3,4)}$.

Tabela 1. Valores médios de $\mathrm{pH}$, temperatura, massa específica (ME), perdas de gases (PG), perda de efluentes (PE) e índice de recuperação de massa seca (RMS) de silagem de cana-de-açúcar com adição de inoculante biológico e/ou diferentes fontes de carboidratos

\begin{tabular}{|c|c|c|c|c|c|c|c|}
\hline \multirow[b]{2}{*}{ Variáveis } & \multicolumn{5}{|c|}{ Tratamentos } & \multirow[b]{2}{*}{$\begin{array}{l}\text { CV } \\
(\%)\end{array}$} & \multirow[b]{2}{*}{$P>F$} \\
\hline & $\mathrm{C}$ & CA & $\mathrm{CCS} 20$ & CFT20 & CFC20 & & \\
\hline $\mathrm{pH}$ & 3,24 & 3,32 & 3,25 & 3,17 & 3,24 & 4,63 & 0,7466 \\
\hline Temperatura $\left({ }^{\circ} \mathrm{C}\right)$ & $22,00 \mathrm{~b}$ & $21,75 b$ & $22,50 \mathrm{~b}$ & $22,87 \mathrm{ab}$ & $24,33 a$ & 3,26 & 0,0041 \\
\hline $\mathrm{ME}\left(\mathrm{kg}\right.$ de $\left.\mathrm{MV} \mathrm{m}^{-3}\right)$ & $623,1 \mathrm{c}$ & $616,7 \mathrm{c}$ & $784,3^{\mathrm{a}}$ & $739,8 b$ & $773,2 \mathrm{a}$ & 1,51 & 0,0001 \\
\hline PG (\% MS) & $9,59 \mathrm{a}$ & $3,31 \mathrm{~b}$ & $2,7 \mathrm{~b}$ & $1,64 \mathrm{~b}$ & $4,32 b$ & 38,85 & 0,0001 \\
\hline $\mathrm{PE}\left(\mathrm{kg}\right.$ ton $\left.^{-1}\right)$ & $237,7 a$ & $84,2 \mathrm{~b}$ & $54,8 \mathrm{~b}$ & $50,6 \mathrm{~b}$ & $39,9 b$ & 27,81 & 0,0001 \\
\hline RMS (\%) & $66,37 \mathrm{~b}$ & $81,01 \mathrm{a}$ & $84,28 \mathrm{a}$ & $91,27 \mathrm{a}$ & $90,87 \mathrm{a}$ & 7,82 & 0,0003 \\
\hline
\end{tabular}


Quanto à temperatura, foram observados valores maiores nas silagens do tratamento CFC20, contendo a adição de $10 \%$ de farelo de trigo $+10 \%$ de casca de soja, em relação às silagens dos tratamentos controle, CA e CCS20, não diferindo estatisticamente das silagens do tratamento CFT20 (Tabela 1). Poder-se-iam esperar temperaturas mais elevadas na silagem controle, visto que nesta há maior probabilidade da presença de microrganismos aeróbios que causam o aumento de temperatura durante os processos de respiração e assimilação de substâncias orgânicas ${ }^{(16)}$, entretanto, as maiores porcentagens de matéria seca encontradas nos demais tratamentos pode ter influenciado no aumento de temperatura, uma vez que a liberação de calor pode ser também influenciada pelos maiores valores de matéria seca ${ }^{(17)}$.

Os valores da massa específica (ME) variaram de acordo com os tratamentos, sendo observados valores maiores nas silagens em que foram adicionadas fontes de carboidratos juntamente com o inoculante biológico, em comparação com a silagem controle ou apenas com inoculante bacteriano (Tabela 1). Tais resultados são provenientes da elevação do teor de matéria seca ${ }^{(6)}$ e da facilidade de compactação do material ensilado que a adição de fontes de carboidratos pode causar, resultando em uma maior quantidade de MS de silagem por unidade de volume.

Embora não haja a indicação do valor de massa específica ideal para avaliação em um silo, é recomendado que seus valores estejam entre 550 a $850 \mathrm{~kg}$ de $\mathrm{MV} / \mathrm{m}^{3}{ }^{(18,13)}$. No entanto, altos valores são obtidos apenas em condições bastante favoráveis e, tratando-se de silagens de materiais mais úmidos como gramíneas tropicais, dificilmente serão alcançados ${ }^{(13)}$, o que justifica a utilização de aditivos absorventes na ensilagem dessas espécies.

As perdas de gases (PG), assim como as perdas por efluentes (PE), foram maiores na silagem controle, sendo os outros tratamentos estatisticamente semelhantes entre si (Tabela 1), evidenciando a eficiência da adição do inoculante biológico à base de L. buchneri em reduzir as perdas quantitativas durante a fermentação, visto que este pode controlar o desenvolvimento de microrganismos causadores de perdas por gases e efluentes decorrentes da liberação de $\mathrm{CO}_{2}$ e do próprio crescimento dos microrganismos ${ }^{(3)}$. No presente estudo, a diferença nas perdas de efluentes foi em média $-75,86 \%$ menor nas silagens com inoculante em relação à silagem controle, valores estes superiores aos encontrados por Daniel et al. ${ }^{(19)}$, que observaram que a adição de inoculantes bacterianos à base de Lactobacillus kefiri e Lactobacillus brevis, isoladamente e misturados, reduziu em até $26 \%$ as perdas da silagem.

Quanto ao índice de recuperação da matéria seca (RMS), o menor resultado encontrado foi para a silagem controle, diferindo estatisticamente dos demais tratamentos (Tabela 1). De acordo com Siqueira et al. ${ }^{(3)}$ e Pedroso et al. ${ }^{(20)}$, é possível associar a maior recuperação de matéria seca às menores perdas por gases, tendo em vista que a produção de $\mathrm{CO}_{2}$ por leveduras durante a fermentação é o principal responsável pela redução da recuperação de matéria seca, o que foi observado também neste trabalho, pois os tratamentos que apresentaram maior recuperação de matéria seca foram os mesmos que apresentaram as menores perdas por gases.

Zanine et al. ${ }^{(5)}$ observaram efeito linear crescente da adição de diferentes níveis de farelo de trigo em silagem de capim Mombaça sobre a recuperação de matéria seca, sendo que, segundo esses autores, a adição de $20 \%$ de farelo de trigo já é o suficiente para garantir alta recuperação da matéria seca ensilada. Da mesma forma, Santos et al. ${ }^{(21)}$ observaram que a adição de $1 \%$ e $1,5 \%$ de óxido de cálcio $(\mathrm{CaO})$ ou de carbonato de cálcio $\left(\mathrm{CaCO}_{3}\right)$ favorece o processo de ensilagem da cana-de-açúcar e proporciona maior recuperação de matéria seca em comparação com a silagem controle, apenas inoculada com $\mathrm{L}$. buchneri ou com a adição de $1 \%$ de sulfato de cálcio $\left(\mathrm{Ca}\left(\mathrm{SO}_{4}\right)_{2}\right)$.

Os teores de matéria seca (MS) foram maiores para os tratamentos com adição de fontes de carboidratos 
em comparação com os tratamentos nos quais estas não foram utilizadas (Tabela 2), sendo observados valores maiores para o tratamento contendo a adição de $20 \%$ de casca de soja (CCS20) em relação aos demais. Assim como os valores de massa específica (ME), esses resultados evidenciam o acréscimo no teor de matéria seca ocasionado pelos aditivos absorventes ${ }^{(6)}$, sendo os valores de massa específica diretamente proporcionais aos teores de matéria seca ${ }^{(22)}$. Da mesma forma, Freitas et al. ${ }^{(1)}$ observaram aumentos nos teores de matéria seca da silagem de cana-de-açúcar com a adição de resíduo da colheita de soja em relação ao tratamento controle. Monteiro et al. ${ }^{(9)}$ também observaram mesmo efeito na silagem de capim-elefante quando adicionados produtos alternativos e inoculante bacteriano, assim como Zanine et al. ${ }^{(5)}$, que observaram aumento linear nos valores de matéria seca com a adição de níveis de farelo de trigo durante a ensilagem de capim Mombaça.

Tabela 2. Valores médios da matéria seca (MS), proteina bruta (PB), fibra em detergente neutro (FDN), fibra em detergente ácido (FDA), matéria mineral (MM) e matéria orgânica (MO) de silagem de cana-de-açúcar com adição de inoculante biológico e/ou diferentes fontes de carboidratos

\begin{tabular}{|c|c|c|c|c|c|c|c|}
\hline \multirow[b]{2}{*}{ Variáveis } & \multicolumn{5}{|c|}{ Tratamentos } & \multirow[b]{2}{*}{ CV(\%) } & \multirow[b]{2}{*}{$\mathbf{P}>\mathbf{F}$} \\
\hline & $\mathrm{C}$ & CA & CCS20 & CFT20 & CFC20 & & \\
\hline MS (\%) & $20,98 \mathrm{e}$ & $21,53 \mathrm{~d}$ & $24,07 a$ & $23,69 \mathrm{c}$ & $23,88 \mathrm{~b}$ & 0,30 & 0,0001 \\
\hline PB (\% MS) & $5,27 \mathrm{bc}$ & $5,09 \mathrm{c}$ & $7,48 \mathrm{a}$ & $6,79 \mathrm{ab}$ & $6,99 \mathrm{a}$ & 11,74 & 0,0012 \\
\hline FDN (\% MS) & $55,78 \mathrm{~b}$ & $61,03 \mathrm{ab}$ & $62,22 \mathrm{ab}$ & $68,55^{\mathrm{a}}$ & $66,14 a$ & 5,06 & 0,0032 \\
\hline FDA ( $\%$ MS) & 47,72 & 44,77 & 48,19 & 41,74 & 46,83 & 11,25 & 0,5309 \\
\hline MM (\% MS) & 4,68 & 4,75 & 4,56 & 4,65 & 4,67 & 7,86 & 0,9670 \\
\hline MO (\% MS) & 95,32 & 95,25 & 95,44 & 95,35 & 95,33 & 0,38 & 0,9670 \\
\hline
\end{tabular}

Ao comparar isoladamente os teores de matéria seca das silagens em que não foram adicionadas fontes de carboidratos, observa-se que, no tratamento cana + inoculante, os resultados foram superiores aos do tratamento controle (Tabela 2), sendo esta uma consequência das menores perdas de matéria seca por gases e efluentes ocorridas na silagem em que o inoculante foi utilizado, evidenciando sua eficiência em reduzir essas perdas.

O teor de proteína bruta (PB) foi maior nas silagens com a adição de fontes de carboidratos, porém, os valores obtidos para o tratamento cana + inoculante $+20 \%$ de farelo de trigo não apresentaram diferenças estatísticas em relação ao tratamento controle (Tabela 2). De acordo com Mertens ${ }^{(23)}$, é necessário que os valores de proteína bruta sejam superiores a $6 \%$ para que este nutriente não se torne um fator limitante à fermentação dos carboidratos estruturais pela flora ruminal. Nesse sentido, os valores obtidos com o tratamento controle e com o tratamento cana + aditivo estão abaixo do recomendado, o que, consequentemente, pode causar redução na digestão da fibra no rúmen caso alguma outra fonte de proteína não seja fornecida junto à silagem desses tratamentos. Por outro lado, a inclusão das fontes de carboidratos elevou esse teor e gerou resultados satisfatórios, assim como os encontrados por Freitas et al..$^{(1)}$, que observaram incremento no teor de proteína bruta como resultado da adição de resíduo de soja em silagem de cana-de-açúcar, e Zanine et al. ${ }^{(5)}$, que observaram aumento linear dos valores de proteína bruta como resposta à adição de níveis de farelo de trigo em silagem de capim Mombaça.

Quanto à fibra em detergente neutro (FDN), verificaram-se valores maiores nas silagens dos 
tratamentos CFT20 e CFC20 em relação à silagem controle, porém, não diferiram estatisticamente dos tratamentos CCS20 e CA. Esperava-se encontrar maiores valores de FDN para a silagem controle, uma vez que a elevação no teor de FDN é relativa e ocorre devido à perda de conteúdo celular ocasionada por microrganismos indesejáveis no período de fermentação ${ }^{(7)}$, o qual foi maior no tratamento controle, em que foram observadas maiores perdas de matéria seca. Entretanto, os maiores valores de FDN observados mesmo nas silagens aditivadas com fontes de carboidratos podem ser decorrentes do próprio FDN desses aditivos, uma vez que, no farelo de trigo e na casca de soja, são comuns altos valores de FDN, conforme os encontrados por Zambom et al. ${ }^{(24)}$, Wesendonck ${ }^{(25)}$ e Dos Santos et al. ${ }^{(26)}$. Entretanto, a fibra da casca da soja tem elevada digestibilidade ruminal, o que resulta em elevada produção de ácidos graxos voláteis no rúmen ${ }^{(10,11)}$.

Esperava-se que os valores de FDA também fossem maiores no tratamento controle, uma vez que nesse tratamento foram verificadas maiores perdas durante o processo fermentativo, no entanto, estes não apresentaram diferenças estatísticas entre os tratamentos (Tabela 2). Assim como o ocorrido para a variável FDN, o próprio FDA desses aditivos pode ter influenciado na elevação dos teores de FDA da silagem, não sendo verificada a eficiência desses aditivos em reduzir os valores de FDN e FDA conforme previsto na literatura.

Quanto às variáveis matéria mineral e matéria orgânica, não foram observadas diferenças significativas entre os tratamentos (Tabela 2), indicando que a adição de inoculante biológico e/ou fontes de carboidratos não foi suficiente para influenciar tais características na silagem de cana-de-açúcar.

\section{Conclusões}

A inclusão do inoculante biológico, isoladamente, não foi suficiente para melhorar a qualidade bromatológica da silagem, entretanto, foi eficiente para reduzir as perdas por gases e efluentes e proporcionar maior recuperação de matéria seca.

A inclusão de $20 \%$ da casca de soja ou de farelo de trigo ou a mistura de $10 \%$ de cada um desses aditivos melhorou a qualidade da silagem de cana-de-açúcar, resultando em maior massa específica e melhores características bromatológicas, expressas nos maiores teores de proteína bruta e de matéria seca.

\section{Referências}

1. Freitas AWP, Pereira JC, Rocha FC, Costa MG, Leonel FP, Ribeiro MD. Avaliação da qualidade nutricional da silagem de cana de-açúcar com aditivos microbianos e enriquecida com resíduo da colheita de soja. Revista Brasileira de Zootecnia, 2006, 35(1), 38-47. Disponível em: http://www.scielo.br/pdf/rbz/v35n1/28340.pdf

2. Valvasori E, Lucci CS, Arcaro JRP. Avaliação da cana-de-açúcar em substituição a silagem de milho para vacas leiteiras. Brazilian Journal of Veterinary Research and Animal Science, 1995, 32(4), 224-228. Disponível em: https://www.revistas.usp.br/bjvras/article/view/52113/56163

3. Siqueira GR, Reis RA, Schocken-Iturrino RP, Pires AJV, Bernardes TF, Amaral RC. Perdas de silagens de cana-de-açúcar tratadas com aditivos químicos e bacterianos. Revista Brasileira de Zootecnia, 2007, 36(6), 2000-2009. Disponível em: http://www.scielo.br/pdf/rbz/v36n6s0/08.pdf

4. Ranjit NK, Kung Jr L. The effect of Lactobacillus buchneri, Lactobacillus plantarum, or a chemical 
preservation on fermentation and aerobic stability of corn silage. Journal of Dairy Science, 2000, 83(3), 526535. Disponível em: http://www.sciencedirect.com/science/article/pii/S0022030200749125

5. Zanine AM, Santos EM, Ferreira DJ, Pereira OG, Almeida JCC. Efeito do farelo de trigo sobre as perdas, recuperação da matéria seca e composição bromatológica de silagem de capim-mombaça. Brazilian Journal of Veterinary Research and Animal Science, 2006, 43(6), 803-809. Disponível em: https://www.revistas.usp.br/ bjvras/article/view/26560/28343

6. Silva FF, Aguiar MSMA, Veloso CM, Pires AJV, Bonomo P, Dutra GS, Almeida VS, Carvalho GGP, Silva RR, Dias AM, Ítavo LCV. Bagaço de mandioca na ensilagem do capim-elefante: qualidade das silagens e digestibilidade dos nutrientes. Arq. Bras. de Med. Veterinária e Zootecnia, 2007, 59(3), 719-729. Disponível em: http://www.scielo.br/pdf/abmvz/v59n3/a26v59n3.pdf

7. McDonald, P.; Henderson, A.R.; Heron, S.J.E. The biochemistry of silage. 2.ed. Merlow: Chalcomb Publications, 1991. 340p.

8. Ribeiro RDX, Oliveira RL, Bagaldo AR, Faria EFS, Garcez Neto AF, Silva TM, Borja MS, Cardoso Neto BM. Capim-tanzânia ensilado com níveis de farelo de trigo. Revista Brasileira de Saúde e Produção Animal, 2008, 9(4), 631-640. Disponível em: http://revistas.ufba.br/index.php/rbspa/article/view/1277/714

9. Monteiro IJG, De Abreu JG, Cabral LS, Ribeiro MD, Dos Reis RHP. Silagem de capim-elefante aditivada com produtos alternativos. Acta Scientiarum, 2011, 33(4), 347-352. DOI: http://dx.doi.org/ 10.4025/actascianimsci. $\underline{\mathrm{v} 33 \mathrm{i} 4.12629}$

10. Bach A, Yoon IK, Stern MD, Jung HG, Chester-Jones H. Effects of type of carbohydrate supplementation to lush pasture on microbial fermentation in continuous culture. Journal of Dairy Science, 1999, 82(1), 153160. Disponível em: http://periodicos.uem.br/ojs/index.php/ActaSciAnimSci/article/view/12629/12629

11. Andrade AP, Quadros DG, Bezerra ARG, Almeida JAR, Silva PHS, Araújo JAM. Aspectos qualitativos da silagem de capim-elefante com fubá de milho e casca de soja. Semina Ciências Agrárias, 2012, 33(3), 12091218. Disponível em: http://www.uel.br/revistas/uel/index.php/semagrarias/article/view/8951/10869

12. Maack, R. Geografia Física do Estado do Paraná. Curitiba: Universidade Federal do Paraná e Instituto de Biologia e Pesquisa Tecnológica, 1968. 350p.

13. Jobim CC, Nussio LG, Reis RA, Schimdt P. Avanços metodológicos na avaliação da qualidade da forragem conservada. Revista Brasileira de Zootecnia, 2007, 36, 101-119. Disponível em: https://repositorio.unesp.br/ handle/11449/30785

14. Silva DJ, Queiroz AC. Análises de alimentos (métodos químicos e biológicos). 3.ed. Viçosa, MG: Editora UFV, 2002. 235p.

15. Da Silva EJA, Borgatti LMO, Meyer PM, Marino CT, Rodrigues PHM. Efeitos do teor de carboidratos solúveis sobre as características da silagem de cana-de-açúcar. Revista Brasileira de Zootecnia, 2008, 37(8), 1375-1382. Disponível em: http://www.scielo.br/pdf/rbz/v37n8/v37n8a06.pdf

16. Rezende AV, Rabelo CHS, Rabelo FHS, Nogueira DA, Faria Jr DCNA, Barbosa LA. Perdas fermentativas e estabilidade aeróbia de silagens de cana-de-açúcar tratadas com cal virgem e cloreto de sódio. Revista Brasileira de Zootecnia, 2011, 40(4), 739-746. Disponível em: http://www.scielo.br/pdf/rbz/v40n4/06.pdf

17. Silva JMN. Desenvolvimento de microrganismos e valor nutritivo de silagens de capim-tifton85. Jaboticabal. Universidade Estadual Paulista, 2002. 88p. Tese (Doutorado em Zootecnia) - Faculdade de Ciências Agrárias e Veterinárias, Universidade Estadual Paulista Júlio de Mesquita Filho, Botucatu. disponível em: https:// repositorio.unesp.br/bitstream/handle/11449/104979/silva_jmn_dr_jabo.pdf? sequence=1\&isAllowed=y

18. Ruppel KA, Pitt RE, Chase LE, Galton DM. Bunker silo management and its relationship to forage

Cienc. anim. bras., Goiânia, v.20, 1-10, e-50390, 2019 
preservation on dairy farms. Journal of Dairy Science, 1995, 78(1), 141-153. Disponível em: http://dx.doi. org/10.3168/jds.S0022-0302(95)76624-3

19. Daniel JLP, Checolli M, Zwielehner J, Junges D, Fernandes J, Nussio LG. The effects of Lactobacillus kefiri and L. brevis on the fermentation and aerobic stability of sugarcane silage. Animal Feed Science and Technology, 2015, 205(1), 69-74. Disponível em: http://www.sciencedirect.com/science/article/pii/S037784011500142X

20. Pedroso AF, De Freitas AR, De Souza GB. Fermentation and epiphytic microflora dynamics in sugar cane silage. Scientia Agricola, 2005, 62 (5), 427-432. Disponível em: http://www.scielo.br/pdf/sa/v62n5/25980.pdf

21. Santos MC, Nussio LG, Mourão GB, Schhmidt P, Mari LJ, Ribeiro JL. Influência da utilização de aditivos químicos no perfil da fermentação, no valor nutritivo e nas perdas de silagens de cana-de-açúcar. Revista Brasileira de Zootecnia, 2008, 37(9), 1555-1563. Disponível em: http://www.scielo.br/pdf/rbz/v37n9/ a06v37n9.pdf

22. Pedó LFB, Nörnberg JL, Velho JP, Hentz F, Henn JD, Barcellos JOJ, Velho IMPH, Marx FR. Fracionamento dos carboidratos de silagens de milho safrinha colhidas em diferentes alturas de corte. Ciência Rural, 2009, 39(1), 188-194. Disponível em: http://www.scielo.br/pdf/cr/v39n1/a53cr292.pdf

23. Mertens DR. Regulation of forage intake. In: Fahey Jr GC. Forage quality, evaluation and utilization. Madison: American Society of Agronomy, 1994. p.450-493.

24. Zambom MA, Dos Santos GT, Modesto EC, Alcade CR, Gonçalves GD, Da Silva DC, Da Silva KT, Faustino JO. Valor nutricional da casca do grão de soja, farelo de soja, milho moído e farelo de trigo para bovinos. Acta Scientiarum, 2001, 23(4), 937-943. Disponível em: http://periodicos.uem.br/ojs/index.php/ ActaSciAnimSci/article/view/2648/2169

25. Wesendonck WR. Valor nutricional de diferentes subprodutos do trigo para suínos em crescimento. Porto Alegre. Universidade Federal do Rio Grande do Sul, 2012. 89p. Dissertação (Mestrado em Zootecnia) Faculdade de Agronomia, Universidade Federal do Rio Grande do Sul, Porto Alegre. Disponível em: http:// hdl.handle.net/10183/61336

26. Dos Santos JW, Cabral LS, Zervoudakis JT, Souza AL, Abreu JG, Bauer MO. Casca de soja em dietas para ovinos. Revista Brasileira de Zootecnia, 2008, 37(11), 2049-2055. Disponível em: http://www.scielo.br/pdf/ $\underline{\mathrm{rbz} / \mathrm{v} 37 \mathrm{n} 11 / \mathrm{v} 37 \mathrm{n} 11 \mathrm{a} 22 . \mathrm{pdf}}$ 